\title{
HUBUNGAN ANTARA LINGKUNGAN KELUARGA DAN KEMANDIRIAN BELAJAR DENGAN PRESTASI BELAJAR MATA PELAJARAN PRODUKTIF SISWA KELAS XI SMK NEGERI 34 JAKARTA \\ ${ }^{1}$ Awalia Septyani, ${ }^{2}$ Suyitno, ${ }^{3}$ Daryanto. \\ ${ }_{1,2,3}$ Pendidikan Teknik Elektro, Fakultas Teknik, Universitas Negeri Jakarta \\ 1,2,3 Email : awalia.septyn@gmail.com ; suyitno@unj.ac.id ; daryanto@unj.ac.id
}

\begin{abstract}
The purpose of this study was to determine the relationship between family environment and learning independence with the learning achievement. In this study using the ex post facto descriptive correlative method with a quantitative approach. The population in this study were students of class XI TITL at SMK Negeri 34 Jakarta as many as 68 people. Data collection methods for family environment variables and learning independence using questionnaire models with Likert Scale, while for the variable learning achievement of productive subjects using the method of documentation in the form of pure value Mid-Term Exams. The results showed that the hypothesis test with a significance level of 5\% obtained $r_{\text {count }}=0,711$ and value of $r_{\text {table }}=0,239$ where $r_{\text {count }}>r_{\text {table }}$ shows that there is a relationship between variables, then the value of $F_{\text {count }}=33,23$ and $F_{\text {table }}$ $=3.14$ where $F_{\text {count }}>F_{\text {table }}$ shows that there is a significance between variables and a determination value of 0,505 which indicates that family environment and learning independence together have an effect of $51 \%$ on learning achievement.
\end{abstract}

Keywords : Family Environment, Learning Independence, Learning Achievements of Productive Lessons

\begin{abstract}
Abstrak
Tujuan dari penelitian ini adalah untuk mengetahui hubungan antara lingkungan keluarga dan kemandirian belajar dengan prestasi belajar mata pelajaran produktif. Pada penelitian ini menggunakan metode ex post facto yang bersifat deskriptif korelatif dengan pendekatan kuantitatif. Populasi dalam penelitian ini adalah siswa/i kelas XI TITL di SMK Negeri 34 Jakarta sebanyak 68 orang. Metode pengambilan data untuk variabel lingkungan keluarga dan kemandirian belajar menggunakan kuesioner model angket dengan Skala Likert, sedangkan untuk variabel prestasi belajar mata pelajaran produktif menggunakan metode dokumentasi berupa nilai murni Ujian Tengah Semester. Hasil perhitungan menunjukkan bahwa uji hipotesis dengan taraf signifikan $5 \%$ di peroleh nilai $\mathrm{r}_{\text {hitung }}=$ 0,711 dan nilai $\mathrm{r}_{\text {tabel }}=0,239$ dimana $\mathrm{r}_{\text {hitung }}>\mathrm{r}_{\text {tabel }}$ menunjukkan bahwa terdapat hubungan antar variabel, kemudian nilai $F_{\text {hitung }}=33,23$ dan $F_{\text {tabel }}=3,14$ dimana $F_{\text {hitung }}>F_{\text {tabel }}$ menunjukkan bahwa terdapat signifikansi antar variabel dan nilai determinasi sebesar 0,505 yang menunjukkan bahwa lingkungan keluarga dan kemandirian belajar secara bersama-sama memiliki pengaruh sebesar $51 \%$ terhadap prestasi belajar.
\end{abstract}

Kata Kunci : Lingkungan Keluarga, Kemandirian belajar, Prestasi Belajar Mata Pelajaran Produktif.

\section{PENDAHULUAN}

Berdasarkan observasi dengan guru-guru kelas XI TITL di SMK Negeri 34 Jakarta, diketahui bahwa terdapat beberapa siswa yang tidak mengerjakan tugas rumah sehingga tidak mengumpulkan tugas. Hal tersebut dikarenakan lingkungan keluarga terutama orang tua kurang memperhatikan siswa dalam belajar dan melakukan aktivitas di rumah. Selain itu kurang mampunya siswa untuk belajar mandiri, hal ini ditandai terdapat beberapa siswa yang mengerjakan PR di sekolah dengan meniru pekerjaan teman. Pada kenyataan lain, siswa mengaku belajar pada saat ujian saja bahkan terdapat siswa yang tidak belajar sama sekali, seharusnya siswa belajar dengan kesadaran sendiri sesuai dengan tanggung jawabnya sebagai seorang pelajar. Berdasarkan wawancara dengan guru-guru kelas XI TITL, pada ulangan harian mata pelajaran produktif (Instalasi Motor Listrik, Instalasi Penerangan Listrik, dan Instalasi Tenaga Listrik) masih terdapat beberapa siswa yang mendapatkan nilai di bawah Kriteria Ketuntasan Minimal (KKM). Prestasi belajar yang diperoleh siswa dipengaruhi oleh beberapa faktor. ${ }^{[1]}$ Menurut teori Dalyono (2009: 55) secara garis besar prestasi belajar dipengaruhi oleh 2 faktor yaitu faktor internal dan faktor eksternal. Faktor internal merupakan faktor yang berasal dari dalam diri peserta didik seperti kemandirian belajar, minat, kercerdasan, bakat, dan motivasi. Sedangkan faktor eksternal adalah faktor yang muncul dari luar diri peserta didik misalnya kurikulum, lingkungan keluarga, lingkungan sekolah, sarana dan fasilitas. ${ }^{[2]}$ Penelitian yang dilakukan oleh Dwi Fajar Wijayanto (2014) menyimpulkan bahwa pencapaian prestasi 
belajar yang optimal dalam proses belajar siswa dapat dipengaruhi oleh banyak faktor.

Dari beberapa faktor tersebut, lingkungan keluarga merupakan faktor yang cukup penting dibanding dengan beberapa faktor lainnya karena lingkungan keluarga merupakan lingkungan pertama dan terpenting dalam perkembangan seorang anak. Lingkungan keluarga yang baik dapat dilihat bagaimana orang tua memperhatikan pendidikan anaknya dengan mendampingi anaknya saat belajar, orang tua yang sering meluangkan waktunya untuk bersenda gurau dan berbicara mengenai pelajaran di sekolah, orang tua yang memberikan penghargaan atas prestasi belajar yang dicapai oleh anaknya, orang tua yang memberi contoh agar tidak bermalas-malasan dalam belajar, yang selalu menciptakan suasana rumah yang tenteram, damai, dan harmonis. ${ }^{[3]}$ Lingkungan keluarga yang mempengaruhi hasil belajar mencakup orang tua mendidik, relasi antar anggota keluarga, suasana rumah, keadaan ekonomi keluarga, pengertian orang tua, dan latar belakang kebudayaan (Slameto, 2010: 60). Seorang anak yang dibesarkan dalam keluarga yang selalu menciptakan suasana rumah yang tenang dan memberikan dorongan dalam belajarnya, anak akan timbul rasa semangat belajar, sehingga anak berhasil dan mendapatkan prestasi belajar yang tinggi. ${ }^{[4]}$ Berdasarkan penelitian yang dilakukan oleh Danik Ratri Wulandari (2015) menyimpulkan bahwa prestasi belajar sangat dipengaruhi oleh lingkungan keluarga.

Keberhasilan usaha dalam belajar siswa juga didukung oleh faktor internal, yaitu kemandirian belajar. Kemandirian belajar dapat diawali dengan kesadaran adanya masalah, sehingga menimbulkan niat melakukan kegiatan belajar secara sengaja untuk menguasai suatu kompetensi yang diperlukan guna mengatasi masalah. Kemandirian dalam belajar perlu diberikan kepada peserta didik supaya mereka mempunyai tanggung jawab dalam mengatur dan mendisiplinkan dirinya dan dalam mengembangkan kemampuan belajar atas kemauan sendiri. Kegiatan belajar mandiri berlangsung dengan ataupun tanpa bantuan orang lain. Tugas guru dalam kemandiran belajar adalah menjadi fasilitator, yaitu menjadi orang yang siap memberikan bantuan kepada peserta didik bila diperlukan. Guru tidak mendominasi dalam kegiatan proses belajar tetapi siswa yang berperan aktif dalam proses pembelajaran. Pada kegiatan belajar mandiri siswa memiliki keleluasaan untuk dapat memilih atau menetapkan sendiri waktu dan cara belajarnya tanpa tekanan dari guru/pihak lain. ${ }^{[5]}$ Kegiatan belajar yang mandiri lebih menitik beratkan pada kesadaran belajar seseorang atau lebih banyak menyerahkan kendali pembelajaran kepada diri siswa itu sendiri (Rusman, 2014: 357). ${ }^{[6]}$ Penelitian yang dilakukan oleh Septiana Dwi (2014) menyimpulkan adanya korelasi antara kemandirian belajar dengan prestasi belajar siswa. Penelitian ini bertujuan untuk mengetahui keeratan hubungan antara lingkungan keluarga dan kemandirian belajar secara bersama-sama dengan prestasi belajar siswa. Kajian pada penelitian ini berfokus pada faktor-faktor yang mempengaruhi prestasi belajar yaitu faktor internal berupa kemandirian belajar dan faktor eksternal berupa lingkungan keluarga. Berdasarkan latar belakang yang telah diuraikan, maka peneliti tertarik untuk melakukan penelitian dengan judul "Hubungan antara Lingkungan Keluarga dan Kemandirian Belajar dengan Prestasi Belajar Mata Pelajaran Produktif Siswa Kelas XI Program Keahlian Teknik Instalasi Tenaga Listrik di SMK Negeri 34 Jakarta."

\section{METODE}

Pada penelitian ini menggunakan metode ex post facto yang bersifat deskriptif korelatif dengan pendekatan kuantitatif, yaitu dengan pengumpulan data menggunakan instrumen penelitian, analisis data bersifat kuantitatif/statistik dengan tujuan untuk menguji hipotesis.

Populasi dalam penelitian ini adalah siswa/i kelas XI TITL di SMK Negeri 34 Jakarta sebanyak 68 orang. Metode pengambilan data untuk variabel lingkungan keluarga dan kemandirian belajar menggunakan kuesioner model angket dengan Skala Likert, sedangkan untuk variabel prestasi belajar mata pelajaran produktif menggunakan metode dokumentasi berupa nilai murni Ujian Tengah Semester.

\section{HASIL DAN PEMBAHASAN}

\section{Prestasi Belajar}

Berikut adalah distribusi frekuensi data prestasi belajar yang dapat dilihat pada tabel 1 . 
Tabel 1. Distribusi Frekuensi Data Prestasi

\begin{tabular}{cccc}
\multicolumn{4}{c}{ Belajar } \\
\hline No & $\begin{array}{c}\text { Kelas } \\
\text { Interval }\end{array}$ & Tepi Kelas & Fa \\
\hline 1. & $55-60$ & $54,5-60,5$ & 2 \\
2. & $61-66$ & $60,5-66,5$ & 8 \\
3. & $67-72$ & $66,5-72,5$ & 14 \\
4. & $73-78$ & $72,5-78,5$ & 20 \\
5. & $79-84$ & $78,5-84,5$ & 15 \\
6. & $85-90$ & $84,5-90,5$ & 7 \\
7. & $91-96$ & $90,5-96,5$ & 2 \\
\hline \multicolumn{4}{c}{ Jumlah } \\
\hline
\end{tabular}

Berdasarkan tabel 1. diketahui bahwa variabel prestasi belajar memiliki frekuensi tertinggi yaitu sebanyak 20 siswa yang memiliki nilai pada rentang 73-78, sedangkan frekuensi terendah yakni sebanyak 2 siswa yang terletak pada interval kelas ke 1 yakni antara 55-61 dan interval kelas ke 7 yakni sebanyak 2 siswa antara 91-96. Kemudian hasil lainnya yaitu sebanyak 8 siswa memiliki nilai pada rentang 61-66, lalu 14 siswa yang memiliki nilai pada rentang 67-72, lalu 15 siswa yang memiliki rentang nilai 79-84 dan 7 siswa memiliki rentang nilai 85-90.

\section{Lingkungan Keluarga}

Berikut adalah distribusi frekuensi data lingkungan keluarga yang dapat dilihat pada tabel 2 .

Tabel 2. Distribusi Frekuensi Data Lingkungan Keluarga

\begin{tabular}{|c|c|c|c|}
\hline No. & $\begin{array}{c}\text { Kelas } \\
\text { Interval }\end{array}$ & Tepi Kelas & $\mathrm{Fa}$ \\
\hline 1. & $58-64$ & $57,5-64,5$ & 2 \\
\hline 2. & $65-71$ & $64,5-71,5$ & 8 \\
\hline 3. & $72-78$ & $71,5-78,5$ & 17 \\
\hline 4. & $79-85$ & $78,5-85,5$ & 22 \\
\hline 5. & $86-92$ & $85,5-92,5$ & 12 \\
\hline 6. & $93-99$ & $92,5-99,5$ & 6 \\
\hline 7. & $100-106$ & $99,5-106,5$ & 1 \\
\hline \multicolumn{3}{|c|}{ Jumlah } & 68 \\
\hline
\end{tabular}

Berdasarkan tabel 2. diketahui bahwa variabel lingkungan keluarga memiliki frekuensi tertinggi yaitu sebanyak 22 siswa pada rentang 79-85, sedangkan frekuensi terendah yakni sebanyak 1 siswa yang terletak pada interval kelas ke 7 yakni antara 100-106. Kemudian hasil lainnya yaitu rentang 58-64 memiliki frekuensi 2 siswa, lalu pada rentang 65-71 memiliki frekuensi 8 siswa, lalu rentang 72-78 memiliki frekuensi 17 siswa, lalu 12 siswa terletak pada rentang nilai 86-92 dan 6 siswa terletak pada rentang nilai 93-99.

\section{Kemandirian Belajar}

Berikut adalah distribusi frekuensi data kemandirian belajar yang dapat dilihat pada tabel 3.

Tabel 3. Distribusi Frekuensi Data Kemandirian Belajar

\begin{tabular}{cccc}
\hline No & Kelas Interval & Tepi Kelas & Fa \\
\hline 1. & $52-56$ & $51,5-56,5$ & 2 \\
2. & $57-61$ & $56,5-61,5$ & 7 \\
3. & $62-66$ & $61,5-66,5$ & 12 \\
4. & $67-71$ & $66,5-71,5$ & 22 \\
5. & $72-76$ & $71,5-76,5$ & 13 \\
6. & $77-81$ & $76,5-81,5$ & 8 \\
7. & $82-86$ & $81,5-86,5$ & 4 \\
\hline \multicolumn{5}{r}{ Jumlah } & 68 \\
\hline
\end{tabular}

Berdasarkan tabel 3. diketahui bahwa variabel kemandirian belajar memiliki frekuensi tertinggi yaitu antara 67-71 memiliki frekuensi sebanyak 22 siswa, sedangkan frekuensi terendah yang terletak pada interval kelas ke 1 yakni antara 52-56 memiliki frekuensi sebanyak 2 siswa. Kemudian hasil lainnya yaitu pada rentang 57-61 memiliki frekuensi 7 siswa, lalu pada rentang 62-66 memiliki frekuensi 12 siswa, lalu pada rentang 72-76 memiliki frekuensi 13 siswa, lalu rentang 77-81 memiliki frekuensi 8 siswa dan pada rentang 82-86 memiliki frekuensi 4 siswa.

\section{Uji Normalitas}

Berikut adalah perhitungan uji normalitas lingkungan keluarga, kemandirian belajar, dan prestasi belajar yang dapat dilihat pada tabel 4 .

Tabel 4. Uji Normalitas Lingkungan Keluarga, Kemandirian Belajar dan Prestasi Belajar

\begin{tabular}{ccccc}
$\begin{array}{c}\text { Uji } \\
\text { Normalitas }\end{array}$ & Dk & $\begin{array}{c}\boldsymbol{\chi}^{\mathbf{2}} \\
\text { tabel }\end{array}$ & $\begin{array}{c}\boldsymbol{\chi}^{\mathbf{2}} \mathbf{\text { nitu }} \\
\text { ng }\end{array}$ & Ket \\
\hline $\begin{array}{c}\text { Lingkunga } \\
\text { n Keluarga }\end{array}$ & 6 & $\begin{array}{c}12,5 \\
9\end{array}$ & 0,494 & $\begin{array}{c}\text { Norm } \\
\text { al }\end{array}$ \\
$\begin{array}{c}\text { Kemandiria } \\
\text { n Belajar }\end{array}$ & 6 & $\begin{array}{c}12,5 \\
9\end{array}$ & 2,196 & $\begin{array}{c}\text { Norm } \\
\text { al }\end{array}$ \\
Prestasi & 6 & $\begin{array}{c}12,5 \\
\text { Belajar }\end{array}$ & 0,230 & Norm \\
al \\
\hline
\end{tabular}

Pada tabel 4. untuk variabel lingkungan keluarga $X^{2}$ hitung $=0,494$, sedangkan $X_{\text {tabel }}^{2}=$ 12,59 , untuk $\alpha=0,05$ dan $\mathrm{dk}=6$. Karena $X^{2}{ }_{\text {hitung }}$ $\leq X_{\text {tabel }}^{2}$ maka dapat disimpulkan bahwa penyebaran data pada variabel lingkungan keluarga berdistribusi normal. Untuk variabel kemandirian belajar $X^{2}{ }_{\text {hitung }}=2,196$, sedangkan $X_{\text {tabel }}^{2}=12,59$, untuk $\alpha=0,05 \mathrm{dan} \mathrm{dk}=6$. Karena $X^{2}{ }_{\text {hitung }} \leq X^{2}$ tabel maka dapat disimpulkan bahwa 
penyebaran data pada variabel kemandirian belajar berdistribusi normal. Untuk variabel prestasi belajar mata pelajaran produktif $X^{2}$ hitung $=0,230$, sedangkan $X_{\text {tabel }}^{2}=12,59$, untuk $\alpha=$ 0,05 dan $\mathrm{dk}=6$. Karena $X_{\text {hitung }}^{2} \leq X_{\text {tabel }}^{2}$ maka dapat disimpulkan bahwa penyebaran data pada variabel prestasi belajar mata pelajaran produktif berdistribusi normal.

\section{Uji Linearitas}

Berikut adalah perhitungan uji linearitas lingkungan keluarga dengan prestasi belajar yang dapat dilihat pada tabel 5 .

Tabel 5. Uji Linearitas Lingkungan Keluarga

\begin{tabular}{|c|c|c|c|c|c|}
\hline $\begin{array}{c}\text { Uji } \\
\text { Linieritas }\end{array}$ & n & $\begin{array}{l}\mathbf{D} \\
\mathbf{k}\end{array}$ & $\begin{array}{c}\mathbf{F} \\
\text { hitung }\end{array}$ & $\begin{array}{c}\mathbf{F} \\
\text { tabel }\end{array}$ & Ket \\
\hline $\begin{array}{c}\text { Lingkung } \\
\text { an } \\
\text { Keluarga } \\
\text { dengan } \\
\text { Prestasi } \\
\text { Belajar }\end{array}$ & 68 & $\begin{array}{l}27 \\
\& \\
39\end{array}$ & $\begin{array}{c}1,37 \\
6\end{array}$ & 1,80 & $\begin{array}{l}\text { Lini } \\
\text { er }\end{array}$ \\
\hline
\end{tabular}

Berdasarkan hasil analisis varians (Anava) pada tabel 5. diketahui nilai variabel lingkungan keluarga dengan prestasi belajar yaitu $F_{\text {hitung }}=$ 1,376 dengan derajat kebebasan (dk) pembilang sebesar 27 dan dk penyebut sebesar 39 dan taraf signifikansi $\alpha=5 \%$, maka diperoleh $\mathrm{F}_{\text {tabel }}=1,80$. Dilihat dari kriteria pengujian yang digunakan, maka diperoleh hasil pengujian hipotesis tersebut menunjukkan $F_{\text {hitung }}<\mathrm{F}_{\text {tabel }}$ maka $\mathrm{H}_{0}$ diterima yang berarti terdapat persamaan linier antara variabel lingkungan keluarga dengan prestasi belajar

Selanjutnya adalah perhitungan uji linearitas kemandirian belajar dengan prestasi belajar yang dapat dilihat pada tabel 6 .

Tabel 6. Uji Linearitas Kemandirian Belajar dengan

\begin{tabular}{|c|c|c|c|c|c|}
\hline \multicolumn{6}{|c|}{ Prestasi Belajar } \\
\hline $\begin{array}{c}\text { Uji } \\
\text { Linieritas }\end{array}$ & $\mathbf{n}$ & $\begin{array}{l}\mathbf{D} \\
\mathbf{k}\end{array}$ & $\begin{array}{c}\mathbf{F} \\
\text { hitung }\end{array}$ & $\begin{array}{c}\mathbf{F} \\
\text { tabel }\end{array}$ & Ket \\
\hline $\begin{array}{c}\text { Kemandir } \\
\text { ian } \\
\text { Belajar } \\
\text { dengan } \\
\text { Prestasi } \\
\text { Belajar }\end{array}$ & 68 & $\begin{array}{c}23 \\
\& \\
43\end{array}$ & $\begin{array}{c}1,12 \\
0\end{array}$ & 1,78 & $\begin{array}{c}\text { Lini } \\
\text { er }\end{array}$ \\
\hline
\end{tabular}

Berdasarkan hasil analisis varians (Anava) pada tabel 6. diketahui nilai variabel kemandirian belajar dengan prestasi belajar yaitu $F_{\text {hitung }}=1,120$ dengan derajat kebebasan (dk) pembilang sebesar $23 \mathrm{dan} \mathrm{dk}$ penyebut sebesar 43 dan taraf signifikansi $\alpha=5 \%$, maka diperoleh $\mathrm{F}_{\text {tabel }}=1,78$. Dilihat dari kriteria pengujian yang digunakan, maka diperoleh hasil pengujian hipotesis tersebut menunjukkan $\mathrm{F}_{\text {hitung }}<$ $\mathrm{F}_{\text {tabel }}$ maka $\mathrm{H}_{0}$ diterima yang berarti terdapat persamaan linier antara variabel kemandirian belajar dengan prestasi belajar.

\section{Uji Hipotesis}

Berikut adalah perhitungan uji Hipotesis korelasi pearson product moment lingkungan keluarga dengan prestasi belajar dapat dilihat pada tabel 7. dan tabel 8. untuk Uji Signifikansi Korelasi. Tabel 7. Uji Korelasi Pearson Product Moment

\begin{tabular}{ccccc}
\hline $\mathbf{n}$ & $\mathbf{a}$ & $\begin{array}{c}\mathbf{r} \\
\text { hitung }\end{array}$ & $\begin{array}{c}\mathbf{r} \\
\text { tabel }\end{array}$ & Ket \\
\hline 68 & 0,05 & 0,697 & 0,239 & $\begin{array}{c}\mathrm{Ha} \\
\text { Diterima }\end{array}$ \\
\hline
\end{tabular}

Tabel 8. Uji Signifikansi Korelasi (Uji t)

\begin{tabular}{ccccc}
\hline $\mathbf{N}$ & $\mathbf{a}$ & $\begin{array}{c}\mathbf{t} \\
\text { hitung }\end{array}$ & $\begin{array}{c}\mathbf{t} \\
\text { tabel }\end{array}$ & Ket \\
\hline 68 & 0,05 & 7,896 & 1,996 & $\begin{array}{c}\mathrm{Ha} \\
\text { Diterima }\end{array}$ \\
\hline
\end{tabular}

Selanjutnya adalah perhitungan uji Hipotesis korelasi pearson product moment kemandirian belajar dengan prestasi belajar dapat dilihat pada tabel 9. dan tabel 10. untuk Uji Signifikansi Korelasi.

Tabel 9. Uji Korelasi Pearson Product Moment

\begin{tabular}{ccccc}
\hline $\mathbf{n}$ & $\mathbf{a}$ & $\begin{array}{c}\mathbf{r} \\
\text { hitung }\end{array}$ & $\begin{array}{c}\mathbf{r} \\
\text { tabel }\end{array}$ & Ket \\
\hline 68 & 0,05 & 0,437 & 0,239 & $\begin{array}{c}\text { Ha } \\
\text { Diterima }\end{array}$ \\
\hline
\end{tabular}

Tabel 10. Uji Signifikansi Korelasi (Uji t)

\begin{tabular}{ccccc}
\hline $\mathbf{N}$ & $\mathbf{a}$ & $\begin{array}{c}\mathbf{t} \\
\text { hitung }\end{array}$ & $\begin{array}{c}\mathbf{t} \\
\text { tabel }\end{array}$ & Ket \\
\hline 68 & 0,05 & 3,947 & 1,996 & $\begin{array}{c}\mathrm{Ha} \\
\text { Diterima }\end{array}$ \\
\hline
\end{tabular}

Selanjutnya adalah perhitungan uji Hipotesis korelasi pearson product moment lingkungan keluarga dengan kemandirian belajar dapat dilihat pada tabel 11. dan tabel 12. untuk Uji Signifikansi Korelasi.

Tabel 11. Uji Korelasi Pearson Product Moment

\begin{tabular}{ccccc}
\hline $\mathbf{n}$ & $\mathbf{a}$ & $\begin{array}{c}\mathbf{r} \\
\text { hitung }\end{array}$ & $\begin{array}{c}\mathbf{r} \\
\text { tabel }\end{array}$ & Ket \\
\hline 68 & 0,05 & 0,446 & 0,239 & $\begin{array}{c}\mathrm{Ha} \\
\text { Diterima }\end{array}$ \\
\hline
\end{tabular}

Tabel 12. Uji Signifikansi Korelasi (Uji t)

\begin{tabular}{ccccc}
\hline $\mathbf{n}$ & $\mathbf{a}$ & $\begin{array}{c}\mathbf{t} \\
\text { hitung }\end{array}$ & $\begin{array}{c}\mathbf{t} \\
\text { tabel }\end{array}$ & Ket \\
\hline 68 & 0,05 & 4,048 & 1,996 & $\begin{array}{c}\mathrm{Ha} \\
\text { Diterima }\end{array}$ \\
\hline
\end{tabular}


Selanjutnya adalah perhitungan uji Hipotesis korelasi pearson product moment lingkungan keluarga dan kemandirian belajar dengan prestasi belajar dapat dilihat pada tabel 13 . dan tabel 14. untuk Uji Signifikansi Korelasi.

Tabel 13. Uji Korelasi Pearson Product

\begin{tabular}{ccccc}
\multicolumn{6}{c}{ Moment } \\
\hline $\mathbf{n}$ & $\mathbf{a}$ & $\begin{array}{c}\mathbf{r} \\
\text { hitung }\end{array}$ & $\begin{array}{c}\mathbf{r} \\
\text { tabel }\end{array}$ & Ket \\
\hline 68 & 0,05 & 0,711 & 0,239 & $\begin{array}{c}\mathrm{Ha} \\
\text { Diterima }\end{array}$ \\
\hline
\end{tabular}

Tabel 14. Uji Signifikansi Korelasi (Uji F)

\begin{tabular}{ccccc}
\hline $\mathbf{n}$ & $\mathbf{a}$ & $\begin{array}{c}\mathbf{F} \\
\text { hitung }\end{array}$ & $\begin{array}{c}\mathbf{F} \\
\text { tabel }\end{array}$ & Ket \\
\hline 68 & 0,05 & 33,225 & 3,14 & $\begin{array}{c}\mathrm{Ha} \\
\text { Diterima }\end{array}$ \\
\hline
\end{tabular}

\section{KESIMPULAN DAN SARAN \\ Kesimpulan}

Dari penelitian dan pengolahan data yang sudah dilakukan, maka dapat disimpulkan:

1. Terdapat hubungan yang positif dan signifikan antara lingkungan keluarga dengan prestasi belajar mata pelajaran produktif siswa kelas XI TITL SMK Negeri 34 Jakarta. Berdasarkan hasil perhitungan koefisien product moment menunjukkan nilai $\mathrm{r}_{\mathrm{yx} 1}=0,697$ dan nilai $\mathrm{t}_{\text {hitung }}=7,896$ lebih besar dari $\mathrm{t}_{\text {tabel }}=1,996$. Maka dapat disimpulkan bahwa kedua variabel tersebut mempunyai hubungan yang positif dan signifikan.

2. Terdapat hubungan yang positif dan signifikan antara kemandirian belajar dengan prestasi belajar mata pelajaran produktif siswa kelas XI TITL SMK Negeri 34 Jakarta. Berdasarkan hasil perhitungan koefisien product moment menunjukkan nilai $\mathrm{r}_{\mathrm{yx} 2}=0,437$ dan nilai $\mathrm{t}_{\text {hitung }}=3,947$ lebih besar dari $\mathrm{t}_{\text {tabel }}=1,996$. Maka dapat disimpulkan bahwa kedua variabel tersebut mempunyai hubungan yang positif dan signifikan.

3. Terdapat hubungan yang positif dan signifikan antara lingkungan keluarga dengan kemandirian belajar siswa kelas XI TITL SMK Negeri 34 Jakarta. Berdasarkan hasil perhitungan koefisien product moment menunjukkan nilai $\mathrm{r}_{\mathrm{x} 12}=$ 0,446 dan nilai thitung $=4,048$ lebih besar dari $\mathrm{t}_{\text {tabel }}=1,996$. Maka dapat disimpulkan bahwa kedua variabel tersebut mempunyai hubungan yang positif dan signifikan.

4. Terdapat hubungan yang positif dan signifikan antara lingkungan keluarga dan kemandirian belajar dengan prestasi belajar mata pelajaran produktif siswa kelas XI TITL SMK Negeri 34 Jakarta. Berdasarkan hasil perhitungan koefisien product moment menunjukkan nilai $\mathrm{r}_{\mathrm{yx} 12}=0,711$ dan nilai $F_{\text {hitung }}=33,225$ lebih besar dari $\mathrm{F}_{\text {tabel }}=3,14$. Maka dapat disimpulkan bahwa variabel bebas secara bersama-sama mempunyai hubungan yang positif dan signifikan dengan prestasi belajar mata pelajaran produktif.

\section{Saran}

Berdasarkan pembahasan dari hasil perhitungan dan kesimpulan yang didapat, peneliti memiliki saran sebagai berikut:

1. Untuk subyek penelitian yaitu siswa kelas XI TITL SMKN 34 Jakarta. Peneliti menyarankan untuk menjalin hubungan dan komunikasi yang baik dengan orang tua, apabila terdapat kesulitan dalam belajar hendaknya berdiskusi dengan orang tua, dan ciptakan keharmonisan dalam suasana rumah, dengan lingkungan keluarga yang baik maka akan mempengaruhi prestasi belajar ke tingkat yang baik pula.

2. Untuk orang tua, dukunglah anak dalam belajar. Luangkan waktu untuk berbicara mengenai pelajaran di sekolah, ciptakan suasana rumah yang nyaman, dan berikan penghargaan atas prestasi belajar yang dicapai agar ia merasa semangat dalam belajar sehingga memperoleh prestasi belajar yang baik di sekolah.

3. Untuk Kepala Sekolah dan Kepala Jurusan Teknik Instalasi Tenaga Listrik SMKN 34 Jakarta, agar terus memberikan bimbingan kepada siswanya untuk menumbuhkan kemandirian dalam belajar agar ia memiliki inisiatif, bertanggung jawab atas apa yang dilakukan, dan memiliki motivasi belajar yang tinggi.

4. Untuk peneliti selanjutnya sebagai bahan masukan dan pengetahuan untuk melakukan penelitian sejenis diharapkan mampu menemukan variabel lain yang 
lebih luas dan variatif sehingga dapat menambah hasil-hasil penelitian.

\section{DAFTAR PUSTAKA}

[1] Dalyono. 2009. Psikologi Pendidikan. Jakarta: Rineka Cipta.

[2]Fajar, Dwi. 2014. Pengaruh Lingkungan Belajar dan Kemandirian Belajar Terhadap Prestasi Belajar siswa kelas VIII SMP Muhammadiyah 1 Pengaruh Lingkungan Belajar dan Kemandirian Belajar Terhadap Prestasi Belajar siswa kelas VIII SMP Muhammadiyah 1. Skripsi: Universitas Muhammadiyah Purworejo.

[3]Slameto. 2010. Belajar dan Faktor-Faktor yang Mempengaruhinya. Jakarta: Rineka Cipta.

[4]Ratri, Danik. 2015. Hubungan antara Lingkungan Belajar dan Minat Belajar dengan Prestasi Belajar Pengantar Administrasi Perkantoran Siswa Kelas X Kompetensi Keahlian Administrasi Perkantoran SMK Negeri 1 Bantul. Skripsi: UNY.

[5]Rusman. 2014. Model-model pembelajaran. Jakarta: Rajawali Pers.

[6]Dwi, Septiana. 2014. Hubungan antara Kemandirian dan Motivasi dengan Hasil Belajar Standar Kompetensi Mengelola Peralatan Kantor Siswa Kelas X Administrasi Perkantoran SMK Muhammadiyah 2. Skripsi: UN 